\title{
Pediatric obesity highlight: looking into the future
}

\author{
International Journal of Obesity (2005). doi:10.1038/sj.ijo.0802902 \\ Published online 14 January 2005
}

January 2005 for the International Journal of Obesity is the first anniversary of the Pediatric Highlight Issues. Pediatric Highlights is an innovative and well-received decision by the Editorial Board, which has allowed high-quality pediatric obesity research to be showcased.

A review of Medline publications on childhood obesity shows that it is only in the last decade or so that research into childhood obesity has risen in an exponential manner. There are a number of reasons as to why this research should be fostered. Physical changes occur during the years spanning infancy through young adulthood and are apparent both external and internal. Children are not small adults and extrapolation from adult research to children and adolescents should be undertaken with caution. This is particularly true for pediatric body composition assessment that could yield important new information and insights. The manuscripts chosen for this issue are useful examples of this point. Freeman et al ${ }^{1}$ examined the relation of body mass index (BMI) to levels of fat mass and fat-free mass among healthy children and adolescents. The authors concluded that BMI-for-age is a good indicator of excess body fat mass, BMI differences among thinner children being largely due to fat-free mass. These findings confirm and extend prior studies which have demonstrated a strong correlation between BMI and fatness. ${ }^{2}$ Buyken et $a l^{3}$ consider the effects of measurement technique on BMI in children in the early years. The Klein-Platat et al study ${ }^{4}$ illustrates that relationships between anthropometry and physical activity in children are similar to those described in adults. ${ }^{5,6}$ These studies underline the fundamental importance of refining and using appropriate obesity and overweight measures in children.

Another important aspect of research into childhood obesity is that early onset obesity may hold important keys to the understanding of the aetiology of obesity. ${ }^{7}$ The association of childhood and adolescent obesity with current and future co-morbidity underlines the importance of understanding both the natural history of co-morbidity in the obese child and adolescent, and also the effect of interventions on such co-morbidity. Concerns regarding informed consent and the avoidance of coercion are also particularly relevant in pediatric research. These concerns and the added complexity of working with families create a particular challenge to those researchers in the field of pediatric obesity, and may in part explain the paucity of medium to long-term research into the management of childhood obesity. Additionally, in many countries, the prevention of childhood obesity has become a major health focus. Recently, Flodmark et $a l^{8}$ underlined that there are essentially six relevant levels, which should be involved in the prevention of child and adolescent obesity: family (child, parents, siblings), schools, health professionals, government, industry and media. To encompass all six levels in one single study has yet to be attempted. Co-ordination between health care and government are needed to initiate such targeted actions in the future. Given the available evidence base, it is clear that quality research has to parallel any planned intervention.

In 2004, the International Obesity Taskforce (IOTF) published its report on Obesity in children and young people, a crisis in public health. ${ }^{9}$ There were numerous references in the document to areas where there was a research deficit. The burden of obesity morbidity in children and adolescents and the prevention of childhood obesity were two such areas. The authors of the report emphasize that the rising prevalence of childhood obesity observed in most populations, and the increasing frequency of obesity comorbidity in hospitalized children, must represent a significant and increasing burden on global health services. It is also likely that this burden is underestimated, particularly as both childhood obesity and co-morbidity have been demonstrated to track into adulthood. Yet, there are few studies that have attempted to ascertain the cost of childhood obesity to the community. Wang and Dietz ${ }^{10}$ have reported on costs for hospitalized children and youth, a study which found that the most common obesity related co-morbidities accounted for over one-third of pediatric hospitalizations.

This IOTF report also reviewed the studies that have been undertaken on the prevention of child obesity, and concluded that there was a lack of well-conducted, controlled trials of prevention approaches. The report also noted that the research emphasis in childhood obesity was largely directed towards the biology of obesity (genes, hormone, metabolic pathways, etc). While knowledge of the biological aspects of childhood obesity is clearly important, the authors commented: 'obesity is unlikely to prove to be a disorder amenable to a 'magic bullet' solution - there is little likelihood that it can be prevented in the mass of the population through the means of pharmaceutical interventions affecting cell activity, say, or through gene interventions'. ${ }^{9}$ Such solutions are more likely to be found in research that encompasses the many community and social aspects of childhood obesity. ${ }^{8}$ 
Another childhood obesity research area that is lacking in an evidence base is the management of established obesity in childhood and adolescence. The evidence was scrutinized in two recent publications, a Cochrane Review and the Australian National Health and Medical Research Council (NHMRC) Clinical Guidelines. ${ }^{11,12}$ Summerbell et al ${ }^{11}$ concluded that more research was necessary to determine the best way(s) to manage children who were overweight, particularly given the prevalence of the condition and the impact on their psychosocial and physical well-being. Under their search criteria, they identified 18 research studies but found that the majority of these were limited by small numbers. Their conclusion was that 'there is a limited amount of quality data on the effects of programs to treat childhood obesity, and as such no conclusions can be drawn with confidence'.

The Australian NHMRC Guidelines concluded that weight management programs reported modest success in children and adolescents. ${ }^{12}$ The level of evidence was limited to a small number of randomized controlled trials (RCT) or high-quality non-RCT data. It was not possible to ascertain the relative importance of each of the components of standard weight management, including dietary, activity and behavioral change. It was also observed that most studies were performed in tertiary institutions. The research recommendation from these Guidelines was that 'Simple and well-designed intervention studies in obese children and adolescents, which can be translated into usual clinical practice, are urgently needed'.

The awareness of childhood obesity as a major health problem has to be continually raised in society. The continuing upward trends in prevalence of child obesity, and the adverse health implications related to both paediatric and adult obesity, are significant and indicate the need for new strategies to reduce this upward trend in paediatric obesity prevalence. Childhood obesity is also a fertile ground for research and for all the previously mentioned reasons the International Journal of Obesity looks forward to continuing the support of quality research in this area.

K Steinbeck and A Pietrobelli

\section{References}

1 Freedman DS, Wang J, Maynard LM, Thornton JC, Mei Z, Pierson Jr RN, Dietz WH, Horlick M. Relation of BMI to fat and fat-free mass among children and adolescents. Int J Obes Relat Metab Disord 2005; 29: 1-8.

2 Pietrobelli A, Faith MS, Allison DB, Gallagher D, Chiumello G, Heymsfield SB. Body mass index as a measure of adiposity among children and adolescents: a validation study. J Pediatr 1998; 132: 204-210.

3 Buyken AE, Hahn S, Kroke A. Differences between recombinant length and stature measurement in groups of 2- and 3 -y-old children and its relevance for the use of European body mass index references. Int J Obes Relat Metab Disord 2005; 29: $24-28$

4 Klein-Platat C, Oujaa M, Wagner A, Haan MC, Arveiler D, Schlienger JL, Simon C. Physical activity is inversely related to waist circumference in 12-y-old French adolescents. Int $J$ Obes Relat Metab Disord 2005; 29: 9-14.

5 Czernichow S, Bertrais S, Preziosi P, Galan P, Hercberg S, Oppert JM. SU-VI-MAX study 2004. Indicators of abdominal obesity in middle-aged participants of the SU-VI-MAX study: relationships with educational level, smoking status and physical inactivity. Diabetes Metab 30: 153-159.

6 Koh-Banerjee P, Chu NF, Spiegelman D, Rosner B, Colditz G, Willett W, Rimm E. Prospective study of the association of changes in dietary intake, physical activity, alcohol consumption and smoking with 9-y gain in waist circumference among 16587 US men. Am J Clin Nutr 2003; 78: 719-727.

7 Farooqi IS, Keogh JM, Yeo GS, Lank EJ, Cheetham T, O'Rahilly S. Clinical spectrum of obesity and mutations in the melanocortin 4 receptor gene. N Engl J Med 2003; 348: 1085-1095.

8 Flodmark CE, Lissau I, Moreno LA, Pietrobelli A, Widhalm K. New insight into the field of childhood and adolescents obesity: the European perspective. Int J Obes Relat Metab Disord 2004; 28: 1189-1196.

9 Obesity in children and young people. A crisis in public health. Report to the World Health Organization. T Lobstein, L Baur, R Uauy (eds). Obes Rev 2004; 5 (Suppl 1): 1-104.

10 Wang G, Dietz WH. Economic burden of obesity in youths aged 6-17 years: 1979-1999. Pediatrics 2002; 109: E81-E91.

11 Summerbell CD, Ashton V, Campbell KJ, Edmunds L, Kelly S, Waters $\mathrm{E}$. Interventions for treating obesity in children. Cochrane Review Library Protocol first published: Issue 4, 1999; Review first published: Issue 3, 2003.

12 Commonwealth of Australia 2003. NHMRC clinical practice guidelines for the management of overweight and obesity in children and adolescents. ISBN 186496190 2. www.obesityguidelines. gov.au. 